\title{
ARQUITECTURA DE NUESTRO MAL-ESTAR EN LA CULTURA. CONVERSACIÓN CON ALICIA LEONE
}

Mauricio Clavero Lerena Por la Comisión de Publicaciones de AUDEPP 
Alicia Leone es licenciada en Psicología de la Universidad de Buenos Aires (UBA), psicoanalista de niños y adolescentes y miembro fundador del Colegio de Estudios Avanzados en Psicoanálisis.

Es coordinadora del posgrado Clínica Psicoanalítica con Niños y Adolescentes, de la Asociación Argentina de Psiquiatría y Psicología de la Infancia y la Adolescencia (ASAPPIA), que se dicta en Santa Fe en acuerdo con la Asociación de Psicoanálisis Sigmund Freud del Litoral.

Asimismo, es exsupervisora del Equipo de Adolescencia del Hospital de Niños Dr. R. Gutiérrez, del equipo de Primera Infancia del Hospital Alemán y del equipo de Adolescencia del Hospital Ramos Mejía. Hasta el año 2007 fue coordinadora del seminario anual de la Dra. Silivia Bleichmar. 


\section{INTRODUCCIÓN}

Las instituciones científicas y particularmente las psicoanalíticas tienen sus referentes teórico-clínicos. En AUDEPP Silvia Bleichmar posee un espacio de autor que permite integrar diferentes formatos de trabajo y hace posible que los socios y no socios participen de distintas actividades.

Pensar los malestares de la mano de la obra de Bleichmar convoca a recordar su pensamiento, como dice Luis Horstein, usando y haciendo un balance de su patrimonio psicoanalítico. En ese sentido, más que el reconocimiento de la necesidad de insertar al psicoanálisis en la cultura, implica procurar no seguir negando que está inserto y, por lo tanto, poseer una apertura interdisciplinar que permita comprender ampliamente los malestares propios de cada época. Bleichmar convoca a revalorizar el pensamiento como instrumento crítico-creador.

Conversar con la Alicia Leone es volver a Bleichmar y ampliar sus perspectivas desde las resonancias de quien se formó con ella y compartió un vínculo de estrecha amistad. No todas ni todos los psicoanalistas tienen la posibilidad de trasmitir la teoría y la clínica con la claridad y rigurosidad con que lo hace Alicia. Es por eso que le propusimos una actividad científica abierta dentro de nuestra institución, que es sobre la cual se reconstruye esta conversación. La actividad se tituló Arquitectura de nuestro mal-estar en la cultura: El psicoanálisis ante el malestar sobrante, una aproximación a Silvia Bleichmar. 


\section{LA CONVERSACIÓN}

\section{Alicia, gracias por aceptar el desafío de reconstruir la jornada y a partir de aquel insumo conversar sobre la obra de Silvia Bleichmar y su propuesta sobre el malestar sobrante. Gracias por aportar tu cono- cimiento para nuestro espacio de autor y para nuestros lectores de la revista.}

Muchas gracias a ustedes por toda la generosidad con que siempre me han tratado en la institución.

La invitación a esta actividad fue hecha antes de la pandemia. Entonces, iba pensando y leyendo teoría sobre la crisis de subjetividad, sobre el capitalismo absoluto — como lo llama Franco Berardi-y, de repente, estallaron todas las fragilidades institucionales, todo lo que podemos llamar violencia estructural social, y se hizo visible en sus efectos vía pandemia. Al mismo tiempo, esto nos recuerda que todos estamos en una situación, como dice Janine Puget, de mundos superpuestos. Aunque siempre lo estamos, en este momento es muchísimo más intenso, muchísimo más coincidente, y hace que también trabajemos nosotros bajo cierta situación de traumatismo y de incertidumbre; sabemos que todo se está moviendo y no sabemos en qué dirección, es probable que toda la organización geopolítica tenga cambios cuyas consecuencias no podemos prever.

Entonces recordé una frase que decía Silvia: «Toda astilla hace balsa». O sea, uno puede inhibirse - ya sea porque va a dar una supervisión, porque va a orientar un equipo de trabajo, sea lo que fuese-, sentir que es insuficiente, y es cierto. Pero la idea de su frase sostiene el sentido subjetivo de nuestro trabajo cotidiano. 


\section{Alicia, ¿por qué proponés dialogar sobre la arquitectura de nuestro mal-estar?}

Arquitectura me hacía pensar en cómo está construido el malestar. Además, recordé algo que Silvia muchas veces decía con respecto especialmente a los analistas de niños: que no éramos decoradores que cambiábamos una lámpara de lugar, sino que éramos arquitectos, que estábamos trabajando sobre la estructura, en términos de transformar o propiciar estructuras. Y después, al releer El malestar en la cultura (1930), encontré que también Freud usa esta analogía o metáfora: habla del «complejo edificio de nuestro aparato anímico». Cómo pensemos ese complejo edificio va a ser lo que va a definir, a delinear, cómo vamos a pensar los riesgos y dónde consideraremos que los hay en una estructura, para así pensar nuestra manera de intervención. Porque hay algo que permanentemente está en nuestra tarea: definir qué es lo que consideramos un problema, no desde el punto de vista adaptativo, sino desde el punto de vista de algo que pone en riesgo: la subjetividad; y, con ello, cuál podría ser la manera de intervenir. Nuestro objetivo es disminuir el sufrimiento; entonces, tenemos que entender la arquitectura de dicho sufrimiento.

\section{Partiendo, entonces, de esa noción de disminución del sufrimiento, ¿cuál sería el aporte específico del psicoanálisis y, particularmente, el de Bleichmar?}

Podríamos decir que lo específico de la teoría psicoanalítica es el concepto de pulsión, a partir del cual se articulan el de inconsciente y el de represión, como los conceptos centrales que hacen a nuestra disciplina. Freud propone un hombre en el que las pulsiones deben ser dominadas, organizadas en una tópica que posibilite el establecimiento del yo y, por 
lo tanto, del sujeto. La cultura va a ser posible en la medida en que haya transformación pulsional; o sea, lo que a nosotros más nos interesa, en el sentido de dónde está nuestro mètier, es la transformación pulsional. Tenemos opinión formada respecto a qué destinos de la pulsión son más eficaces para resguardar del sufrimiento y cuáles no, entonces nos hacemos cargo de eso y de tomar decisiones en base a eso.

En los llamados escritos sociales hay algunas afirmaciones de Freud que quisiera recordar. En El porvenir de una ilusión (1927), afirma:

Los vínculos recíprocos entre los seres humanos son profundamente influidos por la medida de la satisfacción pulsional que los bienes existentes hacen posible, y en segundo lugar porque el ser humano individual puede relacionarse con otros como un bien él mismo; si éste explota su fuerza de trabajo o lo toma como un objeto sexual. Pero además porque todo individuo es virtualmente un enemigo de la cultura que empero está destinada a ser un interés humano universal.

Esto lo reafirma en El malestar en la cultura (1930), donde agrega una palabra que me interesa para el desarrollo que quiero hacer:

El prójimo no es solamente posible auxiliar y objeto sexual, sino una tentación para satisfacer en él la agresión, explotar su fuerza de trabajo, sin resarcirlo, usarlo sexualmente sin su consentimiento, desposeerlo de su patrimonio, humillarlo, infringirle dolores, martirizarlo y asesinarlo.

Si ponemos en relación estos párrafos, hay dos afirmaciones de Freud que quiero resaltar. La primera es: los vínculos están influidos por la medida de la satisfacción pulsional que permiten las diversas organizaciones sociales. Esto nos lleva a tener que pensar las organizaciones sociales considerando hasta qué punto y de qué manera satisfacen esas 
necesidades pulsionales. Freud no está hablando de las descargas primarias, sino de que incluso todas las transformaciones pulsionales posibles no sustituyen la satisfacción; lo que hacen es que tome un formato que sea posible dentro de una intersubjetividad. La pulsión es nuestro motor para que podamos sentir placer, investir de interés las actividades, etcétera, en la medida en que está ligada, articulada.

La segunda afirmación a resaltar es en relación a la tentación de uso del otro, que me parece muy importante. Son muy fáciles de observar aquellas situaciones donde el otro puede ser objeto de la pulsión para la propia satisfacción o puede ser capturado para placer y sostén del propio narcisismo a costa de desubjetivizarlo.

¿Por qué los analistas podemos decir algo sobre esto? Porque nuestro mismo dispositivo de trabajo lo pone en juego de manera central. Nosotros proponemos un dispositivo analítico en el cual hay una convocatoria a la sexualidad, a la aparición de la pulsión en sus efectos, aunque, cuando aparece en sus formas ligadas, hay una reproducción —si se quiere- de la situación originaria. Sabemos que la transferencia nos pone en un lugar de saber; por lo tanto, es una situación donde la ética en relación al rehusamiento que hagamos de las tentaciones de las que habla Freud es central. Entonces, nuestra propia experiencia en la clínica es la que nos ofrece un territorio de estudio de esta afirmación de Freud. Por supuesto, no estoy hablando de una cuestión burda en la que martirizo cruelmente al paciente, pero sí de la tentación de que el paciente se porte de tal o cual manera.

Me parece que, aunque nuestro campo no es estrictamente pensar las estructuras sociales, nuestro trabajo en la práctica analítica nos está dando permanentemente un campo de tensión en relación a esto. Toda la noción de abstinencia, por ejemplo, no se trata de si le presto o no un libro al paciente, se trata de abstenerme de esto que describe Freud: de abstenerme tanto en el eje pulsional como narcisista. 
Ahora bien, ¿por qué Silvia en medio de estos desarrollos? Porque tuvo un recorrido personal y profesional muy vasto, particularmente como psicoanalista de niños, lo que la llevó al encuentro con el trabajo de Jean Laplanche.

\section{Alicia, ¿cuáles creés tú que son los aportes más importantes de la obra de Silvia Bleichmar a partir de su vínculo con Jean Laplanche?}

Laplanche aporta dos cosas muy importantes. Una es un método de trabajo, trabajo de psicoanálisis le llama, un trabajo en problemática. ¿Qué quiere decir esto? Lo podemos observar en el Diccionario de psicoanálisis, de Laplanche y Pontalis (1967), donde se hace un recorrido por los conceptos, sus desarrollos y las contradicciones y ramificaciones que puedan aparecer en las distintas obras de Freud, en sus diferentes versiones. Así, ningún concepto se cierra, sino que todos están escritos en su evolución.

Entonces, esta lectura que hace Laplanche de la obra de Freud es una lectura que lleva a que vaya viendo el curso que van teniendo las ideas y los momentos de contradicción, los momentos de desvío, los momentos de abandono de una idea y su puesta en juego con otros aspectos que pueden incluso hacer que se cuestione esa decisión freudiana de abandonar una ruta. Se trata de un trabajo en problemática sobre los conceptos, lo que brinda muchísima libertad, ya que de ninguna manera se trata de sacralizar el pensamiento de nadie ni de oponernos, sino de hacerlo trabajar.

\section{A partir de lo que venís diciendo, parecería que Silvia también pudo trasmitir lo fermental de ese encuentro a sus cercanos. ¿Cómo recor- dás ese encuentro con la obra de Silvia, con su persona, y cuánto ello aportó y aporta a tu identidad como psicoanalista?}


En el momento en que me encuentro con Silvia Bleichmar, yo estaba parada desde otra perspectiva teórica; no me pasó como a ella al encontrarse con Laplanche, de sentir que estaba en un impasse. A mí lo que me pasaba en esa época era que no le podía contar al supervisor lo que hacía en el consultorio, porque las posiciones eran talmúdicas. En ese entonces, yo tenía un paciente, un chiquito de siete años, que entre el momento en que le hago el diagnóstico e indico el tratamiento y el momento en que comienzo a trabajar con él, sufre un accidente y como consecuencia pierde la vista.

Cuando me encuentro con él después del accidente, él estando internado, lo primero que me pregunta hecho un bollito (porque estaba terriblemente arrasado) es si yo tenía guardado sus dibujos y para las sesiones me pide caramelos Sugus. (Estos son caramelos con envoltorio de un color asociado a sabores; si digo «dame el verde», estoy pidiendo el de menta y «dame el amarillo» significa el de limón.) Me pedía los colores: pedía el verde, pedía el rojo, pedía el amarillo... ¿La cuestión talmúdica dónde estaba?

Por el modelo de trabajo que dominaba en ese momento, la intervención analítica era indudablemente la interpretación. De hecho, me decían: «Este nene necesita interpretaciones, no necesita caramelos». Estando en los primeros tiempos de la práctica profesional, me preguntaba: ¿qué iba a interpretarle?, ¿qué formación del inconsciente había en esta situación...? Entonces, lo que decidí fue no seguir supervisando y explorar la experiencia con el niño.

Cuando me encontré con los desarrollos de Silvia, me permitieron resignificar lo que pasaba en esas situaciones. Cuando después el niño hacía edificios en arcilla y yo los tenía que pintar, o cuando de repente se reía si yo decía rojo y me decía «Sos una mersa, se dice colorado», veía cómo la cuestión del saber sobre los colores estaba del lado de él y al mismo tiempo iba haciendo una cierta transcripción con los sabores, con el tacto, con otros modos de codificación de la información. 
La clínica no es el lugar donde aplico las teorías, es el lugar donde las pongo a prueba. Entonces, si tengo una teoría que en la clínica no me está sirviendo, no modeliza adecuadamente, no funciona, me dice que es insuficiente o errada, tengo que poder poner en cuestión aquella teoría, no la puedo forzar. No voy a ponerme a interpretar, por ejemplo, porque hay que interpretar. Silvia planteaba que la clínica es el lugar de falsación de las teorías. Su encuentro con Laplanche tenía que ver con temas en relación a las posiciones lacanianas en ese momento, en relación al inconsciente, que le hacían de obstáculo para el trabajo con niños. ¿Podríamos trabajar analíticamente con un niño pequeño desde esa teoría? ¿o teníamos que esperar a que el niño ingresara al lenguaje desde...?

\section{En ese sentido, ¿cuáles fueron los principales aportes de Laplanche al} respecto?

Laplanche aporta un procedimiento de lectura de esos caminos insinuados y no proseguidos de Freud y, además, hace una propuesta conceptual a partir de esto. Dentro de esta propuesta de trabajo sobre los conceptos, va siguiendo la noción de seducción presente en la obra de Freud desde antes de 1897. Y plantea que, cuando Freud abandona la teoría de la seducción, el desarrollo de la teorización sufre un desvío, que va a llamar extravio biologizante, considerando que lleva la teoría freudiana hacia la ruta del endogenismo y las fantasías filogenéticas.

La teoría de la seducción, no pensada como la seducción puntual perversa de un adulto hacia un niño, que generaría después una neurosis obsesiva o la histeria, sino como una teoría generalizada de la seducción, es un camino rico que nos llevaría a la idea de un psiquismo que se funda exógenamente. Y desde ahí propone que, cuando Freud dice «mi neurótica me miente», cuando deja esa ruta, va hacia lo que es la propuesta de lo preformado y lo filogenético. Esto se ve claramente en Tótem y tabú 
(1913) y en El malestar en la cultura (1930), donde la justificación de, por ejemplo, la angustia de castración remite a estructuras sociales míticas: la interdicción edípica relacionada a la horda primitiva, algo que vendría preformado, las renuncias pulsionales asociadas (metafóricamente) a cuestiones de desarrollo biológico o reconstrucciones de la historia de la humanidad, como ser la latencia en relación a las glaciaciones; o sea, transformaciones que estarían preformadas para el psiquismo.

Laplanche propone una ruta que quiebra esto, con lo cual hay algo que es muy interesante que es que las cosas puede que pasen o puede que no y tenemos que dar cuenta cuando no pasan.

Otro aspecto muy importante en las propuestas conceptuales es el realismo del inconsciente. En el El Inconsciente. Coloquio de Bonneval (1960), Laplanche y Leclaire hacen un planteo divergente al planteo de Lacan en relación al inconsciente, con una recuperación de las características del inconsciente descritas por Freud en 1915. Esto se relaciona con los desarrollos que hace Laplanche en un libro que se llama Nuevos fundamentos para el psicoanálisis: la seducción originaria (1987), donde plantea cuáles son los fundamentos que está proponiendo para el psicoanálisis. Allí hace un estudio de cuatro referencias que están presentes en el psicoanálisis en ese momento: el punto de vista biológico, el filogenético, el mecanicista y (aportado por Lacan, no por Freud) el lingüista. Así, plantea que el dominio propio del psicoanálisis se produce por un recorte a partir de esos dominios conexos y en confrontación con estos, por un recorte que no es idéntico a lo recortado, que es fundador, así como es fundador o refundador el gesto que crea la situación analítica, tiene algo específico.

Esto va a llevar a pensar en dos cosas: la constitución del inconsciente como algo que se da en un tiempo real. La noción de inconsciente que estaba manejando Silvia hasta ese momento era un inconsciente que era mítico, no tenía tiempos de fundación; pero si se plantea un inconsciente 
con cierta materialidad que es la realidad psíquica y fundado por represión, por la represión primaria, entonces se está introduciendo la temporalidad, no una temporalidad de la psicología evolutiva («en tal fecha pasa tal cosa», «ese día se largó acá»), pero sí cierta historicidad, que es cercable. O sea que se estaría planteando un inconsciente que tiene que constituirse por represión. Laplanche va a llamarla represión originaria, pero ¿de qué está hablando? Habla de la represión primaria. Si lo ponemos en términos de Freud, cuando este plantea la represión primaria (recordemos el contexto en que lo hace), busca dar cuenta de las histerias, de las neurosis, o sea, de cómo opera la represión secundaria en la represión propiamente dicha. Y ahí plantea que, como requisito lógico, es necesario que haya habido una represión primaria que funcionaría a puro contrainvestimiento. Él lo deja así, cómo un requisito para que pueda explicarse la represión secundaria. Ahora, sí trabajamos los tiempos de fundación del inconsciente y queremos trabajar justamente con la infancia, tenemos que abrir de qué se trata esa represión originaria, o sea que vamos a los orígenes.

¿Qué quiere decir que trabaja a puro contrainvestimiento? La represión secundaria propiamente dicha trabaja quitándole a las representaciones la condición de conciencia, quita la representación palabra; pero Freud también dice que todo lo reprimido primariamente produce una fuerza atractora, se dan las dos cosas en la represión secundaria. Una cuestión también importante es que partir de este planteo que hace Laplanche supone que no se trata de dos etapas, dos tiempos dentro del inconsciente, sino de dos nociones del inconsciente: aquel inconsciente que se organiza por la represión primaria es como un inconsciente parasubjetivo, no es parte de sujeto, es un inconsciente que queda por contrainvestimiento operando por fuera del sujeto. A partir de ahí (de la constitución del sujeto) es la pulsión, la sexualidad infantil. 
Cuando veamos la manera en la que Silvia lo va trabajando en los intentos de ir cercando los movimientos esto puede quedar más claro. Pero ya es un movimiento de Laplanche plantear dos conceptualizaciones del inconsciente: uno es este que es el inconsciente más primario, que es parasubjetivo. En un primer tiempo, diríamos que es presubjetivo; pero, después de constituido el sujeto, es parasubjetivo. Y otro es el inconsciente que se genera por la represión propiamente dicha, que son las zonas opacas del sujeto, o sea, que están dentro del sujeto operando al modo de proceso primario por supuesto. Entonces, esto se va a sostener después en la clínica con niños y es extensible a ciertos aspectos de la clínica con adultos.

Una diferenciación que hace Silvia es entre síntoma y trastorno. El síntoma es una formación de compromiso entre instancias, tiene que ver con la operación de la represión secundaria. Es en torno a lo reprimido que podemos tener un síntoma, pero cuando lo que tenemos son manifestaciones (no pasaría solamente en la infancia, puede pasar en el adulto también) que lo que muestran son fallas o insuficiencias de la represión primaria — como ser que la pulsión no está suficientemente retranscrita, algo no está operando de manera que permite que la pulsión avance-, hablaríamos de trastorno.

$\mathrm{Al}$ respecto quiero tomar también lo que Laplanche va a llamar la situación antropológica fundamental. ¿Qué sería? Al nacer, el bebé va a ser criado por un adulto o varios (no importan cuántos ni si es una estructura familiar o no) y en algún ambiente, es decir, un sujeto humano que tiene una organización psíquica, que posee un inconsciente, que ha sepultado y dejado fuera de su subjetividad la sexualidad infantil, la pulsión en su sentido más fuerte, y que tiene también sistemas narcisistas, que pueden estar reprimidos. Ese sujeto va a encontrarse con ese cachorro humano (al decir de Silvia) desde todo ese sistema psíquico específicamente humano, desde un sistema clivado. 
Esa situación antropológica fundamental sería universal: en cualquier época o lugar, el origen de la humanización del cachorro tiene que ver con un otro que tiene determinada estructuración psíquica y que, desde ahí, da las condiciones necesarias para que ese cachorro se humanice.

Estas propuestas de Laplanche hacen de base para el objetivo que se plantea Silvia: reposicionar la clínica de niños a la luz de la metapsicología, tomando un inconsciente que tiene tiempos de fundación. Esto implica que vamos a tener que estudiar esos tiempos de fundación, revisarlos, observarlos; vamos a tomarlos como una hipótesis para chequearlo con nuestra clínica.

La teoría de la seducción generalizada quiere dar cuenta de la génesis del aparato psíquico sexual del ser humano a partir de la relación interhumana y no a partir de orígenes biológicos. Sostiene que el aparato psíquico del ser humano está, ante todo, volcado a la pulsión, a la pulsión sexual (de vida y de muerte). Acá está planteando la pulsión de muerte como aquello desligado que atacaría las organizaciones psíquicas, y lo desgaja de explicaciones biologistas como las del más allá. Sería una sola energía, dos modos de estar: la pulsión sexual puede estar ligada (pulsión sexual de vida) o estar desligada y como pulsión atacante, demoníaca, empuje ciego, y operar como pulsión de muerte, pero no como muerte del organismo, sino como muerte del sujeto.

Se trata, entonces, de toda una reformulación del conflicto pulsión de vida - pulsión de muerte que plantea Freud, pero donde se le quita todo el sustento filogenético. Esto es importante desde varios puntos de vista. Por un lado, porque el lugar del otro en nuestro psiquismo es directamente fundante. Y, por otro lado, porque implica una hipótesis o un planteo, una propuesta en relación a lo siguiente: los filósofos plantean que hay dos grandes corrientes en relación a cómo pensar el ser humano. Todorov lo hace en La vida en común (2008), donde plantea que hay una hipótesis que sostiene que el ser humano tiene que abrirse a la 
sociedad porque si no se moriría, no podría sobrevivir, y que hay otra hipótesis que dice que el ser humano se constituye en el encuentro con otro, que no es que está cerrado y se abre al otro, porque muchas veces en distintos momentos del Malestar en la cultura (1930), por ejemplo, aparece como que el ser humano no tuviera otro remedio que estar en la cultura porque si no se moriría. En cambio, si yo lo pienso como que el ser humano se constituye desde el otro, el ser humano no tiene opción de no estar en la cultura, puede vivir como un ermitaño en la cultura, pero el otro está presente en los orígenes de ese sujeto. Entonces, ahí tengo una opción intrateórica en relación a la obra de Freud: la opción del sujeto cerrado que tiene que abrirse, que sería la vesícula, el abandono de la alucinación primitiva porque, si no, no se puede vivir; o tengo un sistema psíquico más aproximado, por ejemplo, al propuesto por el proyecto de psicología para neurólogos, por la Carta 52 y demás, donde la problemática para constituirse el sujeto es cerrar el psiquismo, que es lo que hace que no se siga en una descarga inmediata, descarga a cero, el funcionamiento pulsional.

\section{Alicia, recordando preguntas del auditorio de la actividad sobre la que se reconstruye esta conversación, retomaríamos a Laplanche con la posibilidad de pensar si en su obra hay una suerte de afirmación de un monismo pulsional. ¿Podrías desarrollarlo?}

No es un monismo pulsional, es un monismo energético, se podría decir. O sea, en el accionar sobre el bebé quedan inscriptos lo que Laplanche va a llamar mensajes enigmáticos, que van a ser objeto fuente de la pulsión; entonces, en tanto que es pulsión sexual en el sentido más puro, que es generalizado, es una fuerza que tiende a la descarga, una descarga ciega sin miramientos al objeto; es pulsión sexual, pero cuando le agrego el estado de ser ligada o desligada, creo que ahí ya tengo un dualismo. No 
tengo este dualismo desde la raíz en ese sentido, al modo de como lo plantea Freud (pulsión de vida y pulsión de muerte). Es como si él planteara que tan fuerte es la pulsión sexual como específica del ser humano, el hecho de ese plus de excitación. Quizás si pensamos en el Proyecto de psicología (1985), se entiende más la cuestión de que en el encuentro (lo que va a llamar la vivencia de satisfacción) también se produce un plus de excitación, que queda como una exigencia de trabajo de ahí en más que no se termina de evacuar. Cuando decimos que lo autoconservativo se puede evacuar, puedo huir del estímulo, pero no puedo huir de la excitación, que es algo que queda inscripto. Decimos que el bebé, supongamos, es alimentado y que eso, además de calmar lo autoconservativo y resolver las tensiones autoconservativas, también deja inscripciones que son excitatorias y que son la exigencia de trabajo del psiquismo, son las que van a complejizar el psiquismo. Por eso digo que la pulsión sería como la electricidad en ese sentido: tengo que cablearla porque, si no, me incendio. Por supuesto, ¿el bebé qué va a tener?: auxilio del otro para poder cablear. Pero los dos estados de la pulsión arman justamente el conflicto, porque se necesitan dos elementos en general cuando se pone algo en términos de conflicto.

Freud busca explicitar el conflicto, lo va a ir poniendo en distintos términos: pulsiones autoconservativas y pulsiones sexuales, por ejemplo, libido del Yo, libido de objeto; después, la segunda teoría de las pulsiones, pulsión de vida, pulsión de muerte. Entonces, en términos energéticos puros sería un monismo energético, pero es un dualismo pulsional porque tiene que empezar a ligarse, y va a estar ahí lo ligado y lo desligado; ese es el trabajo de complejización del psiquismo. La idea es de un aparato psíquico defensivista tiene que defenderse de esa excitación que va a tender a una descarga directa. 


\section{Entonces, ¿qué aspectos tomaría Silvia Bleichmar de los planteos que se han hecho hasta ahora en cuanto a la función humanizante y la teoría de la seducción generalizada?}

Silvia Bleichmar se plantea, muy explícitamente, reordenar la clínica con niños, pensarla desde esta perspectiva, desde tiempos de fundación. Por eso, opone mito e historia como un tiempo que ya no es mítico, sino que es un tiempo que puede rastrearse. Se pueden rastrear los tiempos de represión originaria, que es la represión primaria, pero llamada originaria porque da origen a la tópica. Entonces, va a plantear que la función humanizante consiste en que el otro humano va a ejercer esa función desde una doble vertiente, por su propia estructuración psíquica, va a tener dos efectos sobre el cachorro. Por un lado, la sexualización (podemos llamarla pulsación) por su propia sexualidad infantil reprimida, que va a causar que en los modos del cuidado haya siempre un plus que lleva a la complejización psíquica. Entonces, de la corriente de la sexualidad infantil reprimida del adulto se inscriben excitaciones que el adulto no sabe que está inscribiendo; por eso, no estamos hablando de la seducción, como hablaba Freud, del padre perverso que abusaba, sino como teoría de la seducción generalizada.

Se trata de algo que el adulto no sabe que está haciendo, pero que al mismo tiempo ofrece narcisización, hace una identificación ontológica con ese cachorro, lo considera un ser humano, le atribuye emociones y características; uno empieza inmediatamente con esto de que frunce la carita y cosas como «No, le molestó que yo me fuera» (es muy fácil de observar la narcisización en ese sentido). Incluso en situaciones donde no está dado tan fuertemente lo amoroso, pero sí está el percibir al otro como un sujeto (por ejemplo: «Este chico me vino a partir la vida»), se lo ve como un sujeto. Por supuesto que no da lo mismo si la recepción es amorosa o no, pero lo que importa es cómo se articula toda una línea que 
tiene que ver con la sexualidad y toda una línea que tiene que ver con el narcisismo, que son dos ejes que se van a mantener articulados y pueden entrar en conflicto en todos los sujetos.

Entonces, en la constitución del psiquismo del niño tendríamos ese primer tiempo de la sexualidad, pero sigue habiendo aportes que van a posibilitar que aparezca el narcisismo como un nuevo acto psíquico; dentro de esto que se va inscribiendo, como precipitado, representación que le va a pasar a ser investida de manera más estable. Así, vamos a tener lo que sería un primer tiempo del narcisismo y un segundo tiempo de la sexualidad. O sea, el primer tiempo es el de la sexualidad en ese sentido de la inscripción desde el niño, el segundo tiempo de la sexualidad es el primer tiempo del narcisismo. No estoy hablando de forma tajante, sino que hay que ir viendo dentro de estas etapas — que no son etapas en realidad, sino tiempos lógicos no cronológicos - la manera en que esto va organizándose. Porque ¿por qué es posible que aparezca el narcisismo?, porque aparece la posibilidad de retranscripciones, hay una cantidad de aportes a cierta ligazón de esa excitación pulsional, que incluso aparecen en Freud como la cuestión de hamacar los ritmos. No se trata solo de lo que le dicen al bebé y demás, sino de los ritmos, los modos de cuidado, los soportes concretos que tiene ese ejercicio de la función humanizante. Todo ello va poniendo a lo pulsional en condiciones de poder caer bajo la represión originaria, en la medida en que se va constituyendo en el narcisismo y se va, entonces, haciendo posible el sujeto. En tanto que el sujeto puede empezar a aparecer, el funcionamiento pulsional directo tiene que quedar acotado.

Acá hay una cuestión que es interesante también para lo que tiene que ver con el malestar y la aparición de la angustia. Cuando nosotros decimos: «la pulsión queda reprimida primariamente por contrainvestimiento», ahí estamos usando contrainvestimiento porque estamos hablando de fuerzas. Pero ¿qué es lo que consolida a ese contrainvestimiento?: las identificaciones que constituyen al sujeto. A partir de que se 
constituye esto, tenemos la fuente de angustia, porque ¿qué sería lo que pone en riesgo al sujeto, la existencia misma del sujeto?: la pulsión desligada. Por ende, tenemos dentro del mismo origen de la estructuración psíquica la fuente de la angustia, no necesitamos buscarla en el exterior y en las fuerzas de la naturaleza; el origen de la angustia no tiene que ver con la posibilidad de la representación de la muerte física. Cuando el niño comienza a experimentar angustia en el octavo mes, no tiene la más pálida idea de que puede morirse el organismo; la angustia empieza ligada en la escena central, que es la posibilidad de que esa organización que sostiene mi subjetividad sea atacada por un funcionamiento primario, por la pulsión, y que me desarticule, que genere el desmantelamiento de la subjetividad.

Acá Silvia va hacer un planteo que es muy interesante, de los aportes más importantes de su teoría: el Yo cuando se constituye se hace cargo de la función de autopreservación y de autoconservación, que son dos cuestiones diferentes. La autoconservación es aquello que tiene que ver con conservar la vida, con cuidar la dimensión corporal, biológica del sujeto; la autopreservación tiene que ver con aquellos enunciados identificatorios que constituyen al sujeto y que lo constituyen, además, como alguien amable, alguien digno de ser amado. Así pues, en la infancia, en la constitución del Yo - que tiene toda una serie de tiempos que es importante tomar en cuenta, porque de la angustia del octavo mes al niño de cuatro años pasan y se complejizan unas cuantas cosas- primero va a estar lo autopreservativo. Es muy fácil observar cómo la primera función de conservación del sujeto es autopreservativa desde los enunciados identificatorios, no es del riesgo de la vida; incluso el niño no tiene mucha noción del riesgo de vida hasta que no es bastante más grande. Se empieza a preocupar mucho antes por la preservación, tanto en términos del valor de sí mismo como de mantener esos enunciados identificatorios; de la posibilidad de estar vivo o no se ocupan los adultos. A los 5 años más o menos empiezan con la 
preocupación por la muerte de los demás y después por la muerte propia, pero es una función que aparece después y ya puede entrar en conflicto una con otra: puede pasar que por la autoconservativa se pone en riesgo la autopreservativa, cosa que es muy fuerte en las características sociales actuales (actual no solo por la pandemia, sino desde antes).

Hay una frase de Freud en El malestar en la cultura (1930) que me gustó: "Vuelvo a decir que una cultura que deja insatisfecho a un número tan grande de sus miembros y los empuja a la revuelta, no tiene perspectiva de conservarse de manera duradera ni lo merece». Me encantó lo de «ni lo merece» como una cuestión fuerte en esta situación. En muchas situaciones, las decisiones a tomar para mantener lo autoconservativo pueden entrar completamente en conflicto con el autopreservativo, con seguir siendo quien se es para seguir viviendo, para ganar el dinero, para tal cosa, para tal otra. Es una situación muy compleja y me parece importante que haya elementos para poder pensarlo en términos de conflictos.

\section{Estos desarrollos nos van llevando hacia la propuesta de Silvia Bleichmar de diferenciar sujeto ético de sujeto disciplinado. ¿Podrías desarrollarlo?}

Si pensamos estos modos en que el psiquismo se origina, tenemos un primer conflicto estructural, que es entre autoerotismo, en el sentido de la pulsión descargándose en el objeto de la pulsión, y el narcisismo, donde el objeto es objeto de amor y de odio, pero es objeto total, ya no es objeto parcial. En relación a la dualidad pulsional, esto también nos permite ver cómo la pulsión de muerte estaría mucho más relacionada con objetos parciales y la pulsión de vida con objetos totales; o sea que hay una cantidad de indicadores que podemos tomar para pensar el estado de ligazón de una pulsión en el sentido de que esté más cerca de la destrucción o 
más cerca de Eros. El segundo tiempo del narcisismo tendría que ver ya con la constitución de las instancias ideales.

Hay un trabajo muy intenso de Silvia en relación a lo que es la producción del sujeto ético (que incluso fue un seminario completo de un año) y que es una cuestión muy interesante también en el sentido de que permite diferenciar lo que ella llama sujeto disciplinado de sujeto ético. Esto se relaciona con lo que plantea Freud cuando dice que el sentimiento de culpa aparece como un estadio superior a la cultura, por internalización del superyó, donde ya el sujeto disciplinado sería aquel que se comporta como la sociedad espera porque no quiere ser castigado o descubierto. Esto nos permitiría pensar mucho sobre el tema de la corrupción, que creo que es un tema que los psicoanalistas deberían pensar en profundidad.

La corrupción tiene que ver con sujetos disciplinados en términos de la estructura y con el uso de la desmentida. Allí hay una cuestión donde no se genera una culpa, y el uso de la desmentida también lo refuerza, donde se invisibilizan las consecuencias concretas de la corrupción sobre las personas. Esto va desde cuestiones que podemos pensar en términos de la crianza de un niño en la escuela, a situaciones sociales mucho más potentes, para poder evaluarlas en su daño real.

El tema del sujeto ético también tiene que ver con que la ética, para ser tal, tiene que ejercerse con los seres humanos, no solo con los que se me parecen, porque ahí hay una cuestión de cómo recorto al semejante. En esa articulación entre un origen del Yo que tiene que romper lo especular, pero que queda en la lógica del Yo placer purificado, lo que va a quedar es la lógica de la indiferencia o de la agresión. Cuando nosotros decimos que la primera manera o el primer criterio del Yo para diferenciar lo propio de lo no propio es en el Yo placer purificado, estamos diciendo: «todo lo que es bueno me pertenece, el resto no existe». Y si después existe por insistencia porque está ahí, va a generar agresión, lo quiero aniquilar. Entonces, tiene que haber toda una serie de transformaciones para 
que el otro pueda existir en su diferencia y yo no lo tenga que aniquilar, porque el otro no es una amenaza para mí, no lo vivo como una amenaza para mí, el otro es un sujeto humano al que capaz puedo odiar y puedo agredir, pero es un sujeto humano.

\section{En base a tu desarrollo, ¿qué distinguiría la propuesta de Bleichmar de otras en relación a su postulación sobre el concepto de agresividad?}

Una diferencia que plantea Silvia en Dolor país (2002), que me parece que tiene que ver con esto, es la agresividad justamente como algo bueno: me enfrento a un otro que me ofrece resistencia a mis deseos, a mis propuestas, pero el otro es un ser humano, puedo odiarlo, puedo querer destruirlo, pero es un ser humano. Ella la diferencia del sadismo, que sería una pulsión menos ligada que tiene que ver con el placer de producir dolor al otro. Y asimismo la diferencia de la crueldad porque dice que esta es una combinatoria de ambas cosas, agresividad y sadismo, porque implica reconocer que el otro es un ser humano, pero proponerse destituirlo de ese lugar por medio del dolor (el ejemplo más extremo sería la tortura).

En La construcción del sujeto ético (2011), Silvia plantea otra manera que es muy actual, que se va a relacionar con lo que Hannah Arendt llamaba la banalidad del mal. Dice:

Es un modo de operar que no es intrínsecamente cruel, sádico o siquiera agresivo, es un desconocimiento liso y llano de la existencia del otro, en la ausencia de todo reconocimiento de lo que se produce en el otro como semejante, en la desarticulación de toda empatía.

Esto es algo que se puede ver en muchísimas medidas políticas, sociales y económicas, y en muchísimas posiciones; incluso en comentarios 
de las personas donde se articula la cuestión del extraño y de la indiferencia ante el sufrimiento de ese extraño.

Alicia, en la actividad abierta surgía una pregunta que queremos traer a esta conversación. Con esto de que la hominización no es un simple desarrollo filogenético y que, en consecuencia, la ontogenia o el desarrollo psíquico del sujeto puede darse de una manera u otra en función de factores no solo biológicos, sino también - y tal vez con mayor incidencia- de tipo cultural, ¿no te parece que es el espacio donde el psicoanálisis convoca a la reflexión filosófica, sobre todo a la interrogación ética? ¿Podría rastrearse un recorrido de este tipo en los temas que progresivamente va tomando Silvia Bleichmar en su obra?

Sí, yo creo que ese justamente es el punto donde la cuestión del sujeto ético tiene tanta fuerza, justamente porque no viene dado, sino que es algo que se va a tener que establecer. Por ejemplo, en ese adulto que humaniza al cachorro, la ética ¿en qué consiste?: en no apropiarse de ese cachorro.

Pensar de esta manera el psiquismo nos lleva a tener que diferenciar entre constitución del aparato psíquico y producción de subjetividad. Entonces, constitución del aparato psíquico es la necesariedad universal para el ser humano de organizar una tópica. Podríamos decir que sí es específico del ser humano. La pulsión, el realismo psíquico, la fantasía..., lo que sería para la imaginación radical de la que habla Castoriadis, podríamos decir que en todas las épocas el ser humano tuvo que hacer algo con eso, tuvo que organizar un inconsciente para poder existir. Podríamos decir que el ser humano siempre soñó; si soñó, es porque tenía una tópica organizada. 
Ahora, lo que significaban los sueños, las características de la subjetividad, los contenidos identificatorios, las propuestas de valor, las maneras de significación de las cosas..., todo es epocal. En ese sentido, el complejo de Edipo, por ejemplo, el patriarcado y demás, son construcciones narrativas, esquemas narrativos que aporta la cultura para que el sujeto se ubique de alguna manera, pero son epocales, no son intrínsecos a una supuesta naturaleza humana.

Entonces, la ética no se sostendría en lo que la época me dice que corresponde, sino en el posicionamiento en relación a la pulsión. La ética consistiría radicalmente en que el otro no puede ser objeto de mi pulsión, no puedo destituirlo como sujeto, porque lo que a mí también me destruye sería que la pulsión me destituya como sujeto. Así, yo estoy poniendo, como psicoanalista, la raíz de la ética en el mismo campo de origen de la subjetividad; después, las morales de cada época pueden decir distintas cosas. Por eso creo que esta cuestión de que, si el psicoanálisis nace - como dice Castoriadis-y se sostiene en determinado momento histórico y en determinada perspectiva humanista, eso le da un posicionamiento ético, ya no hay relativismos. Hay ciertas cosas que no dependen de tal o cual otra, hay ciertas cosas que no son negociables; aquello que destruye al sujeto, que desmantela la subjetividad, donde yo me estoy apropiando del otro, ya sea que me estoy apropiando del otro porque me parece mejor que mi paciente estudie tal cosa, “¿cómo va a dejar la facultad, qué van a pensar los papás? mejor que...”, de esto a cuestiones de la esclavitud por ejemplo, sociales digamos, a cuestiones así de degradación del ser humano, pero me estoy apoyando en esto, partiendo de esto, no me estoy apoyando en un enunciado externo epocal, después toma los formatos de época, pero yo puedo pensarlo desde ahí.

Silvia hace todo un desarrollo en relación a cómo se va constituyendo el sujeto ético. Por ejemplo, plantea que la ética no viene a partir de que el complejo de Edipo decanta en el Superyó, sino que viene previamente 
por el rehusamiento, se hace el rehusamiento a la descarga pulsional por amor al otro, el niño renuncia a las heces, al placer, a la destrucción y demás por amor al otro, que es también amor a la imagen propia. Entonces, hay un origen del sujeto ético que es previo al Edipo; su origen ya no tiene que ver básicamente con la angustia de castración, por ejemplo, porque me amenazan. Incluso, como propone Laplanche, la renuncia edípica, que es muy observable en la clínica, se hace también por amor al rival: si no hay amor al rival no hay nada que propicie la renuncia. Esta se hace por amor, no se hace por temor, y esto es importante hasta en cuestiones que vemos cotidianamente. Pensémoslo en este sentido: nadie deja algo que lo perjudique simplemente porque sepa que lo perjudica; por ejemplo, nadie deja de fumar porque va a tener un cáncer de pulmón, deja de fumar si eso entra en conflicto con un deseo de preservarse, no por la información.

Los mecanismos de defensa son para evitar la angustia, no son para resolver las cosas; es más, muchas veces van en contra de que podamos resolver los problemas.

\section{A partir de la noción de malestar sobrante y de la noción de transmisión intergeneracional, ¿cómo pensás estos conceptos en relación a esto último que enunciabas sobre la búsqueda de una autoridad como po- sibilidad de figura que dé respuestas?}

Malestar sobrante está referido a la noción de Marcuse. Él habla de represión sobrante porque la hipótesis del malestar que él tiene es en relación a una sociedad que reprime, mientras que lo que plantea Silvia no es tanto una sociedad así, sino una que desmantela o no ofrece soportes identificatorios. Hay una cantidad de escritos al respecto; por ejemplo, un sociólogo y escritor muy interesante en este sentido es Richard Sennett. Él tiene varios libros, pero hay uno que se llama La corrosión del carácter 
del capitalismo actual. Las consecuencias personales del trabajo en el nuevo capitalismo (2002), donde muestra cómo las características que la sociedad propicia para ser eficaz en el trabajo son características que van a contramano de lo que es necesario para armar buenos lazos sociales.

Yo trabajé esto en relación a las condiciones para la responsabilidad parental, cómo para hacerse cargo de un cachorro uno necesita un proyecto a largo plazo. Sennett hace todo un desarrollo en relación a cómo de la responsabilidad se pasa a la coordinación, y a mí me parece importante ligarlo con la propuesta del psicoanálisis de levantar la represión. Esta es una solicitud a la responsabilidad en el mismo sentido en que Freud plantea levantar la represión en casos de neurosis. Pero él no plantea levantar la represión para ver cuál es el deseo, sino que dice que eso tiene que ser sustituido por el juicio. El hecho de que haya quedado en la traducción como juicio de condenación para mí es un problema porque queda muy ligado en nuestra escucha como la represión sobrante. Pero cuando se refiere al juicio, él se refiere a que el sujeto esté en condiciones de soportar, conectarse con deseos que le generan angustia y tomar una decisión.

Me parece que cuando Silvia habla del sujeto ético también se relaciona con esto y Castoriadis lo plantea de una manera que me parece muy interesante. Él dice que el psicoanálisis tiene un propósito, que es un sujeto reflexivo y autónomo. Pero ¿a qué se refiere con un sujeto autóno$m o$ ? Se refiere a un sujeto que sea capaz de darse sus propias leyes desde una ética, no de hacer lo que se le antoja. Ahí hay una contradicción, que trabaja de una manera muy interesante, en relación a la formación de Freud de las tres profesiones imposibles, en el sentido de que el sujeto se constituye también a partir de la materialidad que le da una cultura, de las significaciones imaginarias sociales, y que para ser autónomo debería poder posicionarse en relación a esa sociedad heterónoma. Pero autónomo sería que me hago cargo; en cambio, la represión es desconocer 
(represión secundaria) es porque resulta insoportable conectarme con algo de mi deseo y poder desde ahí decidir.

Entonces, los tres, Bleichmar, Freud y Castoriadis, suponen de una manera más o menos explícita que el dominio sobre la angustia de muerte, como muerte del Yo representada como muerte del organismo, pero también como desmantelamiento de los soportes identificatorios, está en el núcleo del trabajo psicoanalítico. Un sujeto autónomo es un sujeto que puede soportar la angustia de muerte. En ese punto aparece a su vez la idea de que se puede ligar con coraje, pero no con coraje en el sentido de "me hago la canchera», sino en el sentido de poder soportar estas tensiones. Esto también me parece que es una cuestión importante en cuanto a nuestra función.

\section{Alicia, recordando a Ariel Viguera, ¿te parece que hay en el modelo de Silvia una metapsicología del Yo en la obra y que es fecunda para pensar las subjetividades actuales a resguardo de pregnancias ideoló- gicas de la formación hegemónica?}

Yo pienso que sí. En realidad, creo que lo que Silvia aporta permite posicionarse en términos de determinadas ideologías, en el sentido de que está aportando, está resaltando, una teoría sobre el origen del sujeto que supone un posicionamiento en relación a un otro; y que desde ahí sí se podría pensar en términos ideológicos. Por ejemplo, podríamos pensar que desde esta posición metapsicológica los totalitarismos claramente no tendrían sostén, porque estamos hablando de un dominio sobre el pensamiento de otros. La factibilidad de sistemas que se sostengan sobre la máxima transformación pulsional, como dice Silvia en el epígrafe de uno de los libros, "Con el optimismo de la esperanza y con el escepticismo de la inteligencia», pero yo creo que sí podemos evaluar si se quiere, usar criterios para pensar ideologías que tienen que ver con 
esa metapsicología del Yo, pienso que los totalitarismos son un ejemplo muy claro. Incluso acuerdo personalmente cuando Freud plantea cierto escepticismo con la Revolución rusa, más allá de todo lo que es el idealismo en el sentido de no subestimar la dificultad que implica la cantidad de transformaciones que tiene que tener el Yo para llegar a la subjetividad ética. Entonces, pienso que toda ideología que se sostenga en un sujeto ético, para mí es mucho más... consistente; capaz que es difícil de sostener porque implica mucha transformación de la subjetividad, pero es a lo que uno está apuntando. Cuanto mayor complejización del psiquismo, más posibilidades tenemos de poder soportar la diferencia y no eliminar al otro, no desmentir las consecuencias de nuestras acciones por acción o por omisión.

\section{¿La construcción psíquica del cachorro humano se conforma en la intersubjetividad familiar y sociocultural?}

Siempre se va a conformar en algún tipo de trama social, que puede ser familiar o no familiar; o sea, la situación antropológica fundamental no es dentro de una trama forzosamente familiar, es simplemente que sea un cachorro y adultos. En ese sentido, no es intersubjetiva estrictamente tampoco, porque el cachorro no es un sujeto todavía. No estoy aplicando una idea de intersubjetividad en los orígenes del sujeto porque justamente no está el sujeto, el sujeto humano, sino que está el cachorro; entonces, no es que sea intersubjetiva. Nuestra cultura suele ser dentro de una trama familiar, y a esto voy con lo que plantea Silvia en Sostener los paradigmas desprendiéndose de lastre (2011). Yo les hablaba de esta construcción del aparato psíquico diferenciado, de producción de subjetividad. Y dentro de los conceptos centrales del psicoanálisis, tengo que sostener básicamente la sexualidad infantil para seguir siendo quienes somos, esa cuestión autopreservativa: «La sexualidad infantil, su 
descubrimiento como forma principal con la cual se definen los orígenes de la realidad psíquica y su destino insubordinable a la genitalidad como proceso de maduración biológica». O sea, la genitalidad como proceso de maduración biológica no subordina la pulsión, por lo que cae acá toda la idea de las fases de la libido hasta que se llega a una integración. Esto me va a llevar también a redefinir la noción de perversión, que va a ser la desubjetivización del otro, ya no en términos de los modos de ejercicio de la sexualidad, sino que cambia el eje.

$Y$ el otro punto que necesitamos sostener para seguir siendo quienes somos es el lugar del inconsciente, o sea que sexualidad infantil e inconsciente serían lo no negociable, lo que no podría cambiar para poder seguir siendo psicoanálisis; el lugar del inconsciente, su materialidad psíquica caracterizada como asubjetividad radical marcada por la ausencia de intencionalidad y toda referencia del mundo exterior, aun cuando su proveniencia sea de carácter exógeno y sus consecuencias en la aplicación del método.

Considerar al inconsciente en su carácter realista, con un funcionamiento cerrado a toda referencia exterior a sí mismo, a toda intencionalidad, incluido en ello toda apertura subjetivista, la cual debe ser concebida siempre como partiendo del yo, de las instancias abiertas a la intercomunicación.

Lo que está planteando muy fuertemente Silvia en este fragmento de Sostener los paradigmas desprendiéndose del lastre (2011) es que no se trata de un sujeto que está en el inconsciente y que, cuando decimos sujeto del inconsciente, hablamos de un sujeto sujetado a..., afectado por... Incluso a veces a mí me pasa, en el sentido de la complejidad de la relación entre el inconsciente y el sujeto, que digo «sujeto con inconsciente, sujeto de inconsciente», ¿cuál es la relación? 
Sexualidad infantil e inconsciente son aquellos conceptos que no son negociables, después podemos debatir cómo pensamos cada uno de ellos. Y esto hace que, si nosotros dejamos de lado la producción de subjetividad como cosa epocal, los grandes esquemas narrativos, como la estructura familiar, esto nos da libertad para pensarlo de cuestiones más fundamentales. ¿Una pareja de homosexuales puede criar a un niño?, sí, ¿por qué no puede criar a un niño desde este modelo que yo estoy planteando? ¿Un grupo o una tribu puede criar a un niño, donde no haya roles familiares clásicos?, sí, por qué no. ¿La única manera de pautar la sexualidad es el modelo de complejo de Edipo?, no, es un modelo que no es universal tampoco. Lo que sí yo puedo considerar como universal es la interdicción en relación al goce sobre el cuerpo del niño, pero después puede estar presente en esquemas narrativos completamente distintos; en nuestra cultura el esquema es el complejo de Edipo, y en la relación del ideal del Yo y demás en la horda primitiva puede haber una serie de diversos esquemas narrativos, pero no son universales.

Lo que sí sería universal porque lo estoy poniendo en el centro, en el origen de la subjetividad, es la interdicción en relación a que el otro sea objeto de goce, esa sería la interdicción. Después toma otros formatos, eso me permite pensar de manera mucho más rica las diversidades sexuales, los cambios en las estructuras familiares, lo que a veces llaman «nuevas patologías». ¿Desde dónde defino que algo es una patología?, ¿por lo adaptativo? No, sino por este tipo de parámetros.

Para finalizar vuelvo a la propuesta de Laplanche de precisar bien qué sería lo que hace a nuestra propia producción de subjetividad como psicoanalistas para poder pensar las cosas desde ahí. Así podemos lograr dar un aporte, sin diluirnos en otras disciplinas, sino en un diálogo fecundo. En definitiva, todo esto que estamos hablando de transformación pulsional en última instancia es para que se produzca la posibilidad de pensar y que lo podamos preservar. 
Alicia, solo puedo volver a agradecerte por toda esta profunda intervención que hemos intentado reconstruir en formato conversación. Seguramente será insumo para todas y todos nuestros lectores.

Para mí siempre es un placer encontrarme con una institución amiga que me posibilite continuar pensando juntos. Muchas gracias. 
